\title{
Glucagon-like peptide-1 stimulates human insulin promoter activity in part through cAMP-responsive elements that lie upstream and downstream of the transcription start site
}

\author{
Colin W Hay*, Elaine M Sinclair*, Giovanna Bermano, \\ Elaine Durward, Mohammad Tadayyon ${ }^{\mathbf{1}}$ and Kevin Docherty \\ School of Medical Sciences, University of Aberdeen, Institute of Medical Sciences, Foresterhill, Aberdeen AB25 2ZD, UK \\ ${ }^{1}$ Department of Vascular Biology, GlaxoSmithKline Pharmaceuticals, Third Avenue, Harlow, CM19 5AW, UK \\ (Requests for offprints should be addressed to K Docherty; Email: k.docherty@abdn.ac.uk) \\ *(C W Hay and E M Sinclair contributed equally to this work) \\ (M Tadayyon is now at Department of Metabolic Research, Boehringer Ingelheim, 88937 Biberach, Germany)
}

\begin{abstract}
Glucagon-like peptide-1 (GLP-1) is a peptide hormone secreted from the enteroendocrine L-cells of the gut and which acts primarily to potentiate the effects of glucose on insulin secretion from pancreatic $\beta$-cells. It also stimulates insulin gene expression, proinsulin biosynthesis and affects the growth and differentiation of the islets of Langerhans. Previous studies on the mechanisms whereby GLP-1 regulates insulin gene transcription have focused on the rat insulin promoter. The aim of this study was to determine whether the human insulin promoter was also responsive to GLP-1, and if so to investigate the possible role of cAMP-responsive elements (CREs) that lie upstream (CRE1 and CRE2) and downstream (CRE3 and CRE4) of the transcription start site. INS-1 pancreatic $\beta$-cells were transfected with promoter constructs containing fragments of the insulin gene promoter placed upstream of
\end{abstract}

the firefly luciferase reporter gene. GLP-1 was found to stimulate the human insulin promoter, albeit to a lesser degree than the rat insulin promoter. Mutagenesis of CRE2, CRE3 and CRE4 blocked the stimulatory effect of GLP-1 while mutagenesis of CRE1 had no effect. Analysis of nuclear protein binding to the four CREs showed that, while they share some proteins, each CRE site is unique. Stimulation of transcription by GLP-1 through CRE2, CRE3 and CRE4 resulted in altered protein binding that was different for each of the CRE sites involved. Collectively, these data show that the four human CREs are not simply multiple copies of the rat CRE site and further emphasise that the human insulin promoter is distinct from the rodent promoter.

Journal of Endocrinology (2005) 186, 353-365

\section{Introduction}

Glucagon-like peptide-1 (GLP-1) is a peptide hormone secreted by the enteroendocrine L-cells of the small intestine in response to food intake (Kieffer \& Habener 1999, Drucker 2001). GLP-1 plays an important role in lowering blood glucose levels primarily through its ability to potentiate the stimulatory effects of glucose on insulin secretion from pancreatic $\beta$-cells (Holz et al. 1993). It does this through a G-protein-coupled receptor that acts to increase intracellular cAMP levels (Thorens 1992). It also affects blood glucose levels through its inhibitory effects on gastric emptying (Nauck et al. 1997), suppression of appetite (Turton et al. 1996), and inhibition of glucagon secretion from $\alpha$-cells (Komatsu et al. 1989).

GLP-1 is a particularly important regulator of the pancreatic $\beta$-cell with diverse effects on insulin secretion, gene expression, proinsulin biosynthesis and islet cell growth and neogenesis (Drucker et al. 1987, Fehmann \& Habener 1992, Edvell \& Lindstrom 1999, Xu et al. 1999, Stoffers et al. 2000). It also induces differentiation of pancreatic exocrine cells to an endocrine phenotype (Zhou et al. 1999). Multiple signalling pathways and second messengers are involved in the response of the $\beta$-cell to these pleiotropic actions of GLP-1 (Habener 2001).

All of the studies to date on the effects of GLP-1 on insulin gene transcription have focused on the regulation of the rat insulin I promoter. However, since GLP-1 (or its analogues) may have a potentially important role in the treatment of type 2 diabetes (Doyle \& Egan 2001), it is important to understand how it affects expression of the human insulin gene. Expression of the insulin gene is regulated by promoter sequences located up to 
approximately $400 \mathrm{bp}$ from the start site. Although the arrangement of regulatory sequences in the rat insulin I and human insulin promoters is roughly similar (German et al. 1995), there are marked differences in their regulation (Clark \& Docherty 1992, Melloul et al. 2002). Given the importance of cAMP in mediating the effects of GLP-1, we were interested in determining whether the human insulin promoter was responsive to GLP-1 and, if so, also determining the possible role of cAMP-responsive elements (CREs).

\section{Materials and Methods}

\section{Cell culture}

INS-1 cells that were directly descended from the original rat insulinoma cell line developed by Asfari et al. (1992) were cultured in RPMI 1640 containing $11.1 \mathrm{mM}$ D-glucose and $2 \mathrm{mM}$ L-glutamine, supplemented with $10 \%$ foetal bovine serum (FBS), $1 \mathrm{mM}$ sodium pyruvate, $10 \mathrm{mM}$ Hepes balanced salt solution and $50 \mu \mathrm{M}$ $\beta$-mercaptoethanol. Cells were maintained at $37^{\circ} \mathrm{C}$ without antibiotics in a humidified atmosphere containing 95\% air and $5 \% \mathrm{CO}_{2}$. Cells were passaged by trypsinisation and subcultured on a weekly basis.

\section{Radioimmunoassays}

Total insulin-like immunoreactivity (ILI) in INS-1 cell culture medium was detected with an in-house radioimmunoassay employing guinea pig polyclonal antibodies raised against human (pro)insulin (1011 from Linco Research, Biogenesis, Poole, Dorset, UK). Radioimmunoassays were calibrated using rat insulin (Linco Research) and performed in duplicate. ILI results were calculated as $\mathrm{ng} / \mathrm{ml}$ per 24 hours.

\section{Plasmid DNA constructs}

The rat insulin I promoter $(-410$ to $+1 \mathrm{bp})$ construct, pFOXLUC410, and the control vector pFOXLUC were provided by Dr M. German (University of California at San Francisco Medical School, San Francisco, CA, USA). The human insulin promoter construct was generated by PCR amplification of a -364 to $+148 \mathrm{bp}$ fragment of DNA from the plasmid phins300 that contains a Xhol fragment ( $\sim 5 \mathrm{~kb})$ of $\lambda$ hINS-1 (Bell et al. 1980) cloned into the SalI site of pBR322 plasmid. The primers used had the sequence 5'-CGAGCTCGACAGCAGCGCA AAGA-3' and 5'-TCCCCCGGGGGAATGCTTCAC GAG-3'. The amplified fragment was inserted upstream of the firefly luciferase sequences within plasmid pGL3 (Promega) to generate phINS364LUC. The plasmids phINS260LUC and phINS171LUC contained fragments spanning the regions -260 to +148 and -171 to +148 respectively. These were generated by PCR amplification of phins 300 using the following primers: 5 '-CGAGCTCC TGTGAGCAGGGACAG-3' and 5'-TCCCCCGGGG GAATGCTTCACGAG-3' for phINS260LUC, and 5'CGAGCTCAGATCTTCCCACAGAC- $3^{\prime}$ and $5^{\prime}$-TCCC CCGGGGGAATGCTTCACGAG-3' for phINS171LUC.

Mutagenesis of CRE3 at position +18 to generate plasmid phINS171m1LUC was achieved by using the Quik Change Site-Directed Mutagenesis Kit (Stratagene, Amsterdam, The Netherlands) and the following primers: 5'-CCTCCAGGACAGGCTAAATCAGAAGAGGCC ATC $-3^{\prime}$ and its complementary reverse. Mutagenesis of CRE4 at position +61 to generate plasmid phINS171m2LUC was achieved using the primer $5^{\prime}-\mathrm{GT}$ TCCAAGGGCCTTTAAATCAGGTGGGCTCAGG-3' and its complementary reverse. The DNA construct phINS171m3LUC contained mutations at CRE3 and CRE4 using the above primers.

A further construct (phINS356LUC), containing a -356 to +14 fragment of the human insulin promoter in the pGL3 plasmid, was obtained from Dr J. Xu, University of Hong Kong, Hong Kong. Sequencing of this construct showed the presence of an A to G substitution at position -189 that was immediately upstream of the CRE2 consensus sequence. This putative error was corrected by mutagenesis as described above using the primer $5^{\prime}$-GGT CCTGAGGAAGAGGTGCTGACGACC- $3^{\prime}$ and its reverse complement. Similarly, the CRE1 and CRE2 sites were mutated using the following primers and their reverse complements: CRE1 5'-CTGGTTAAGACTCT AATAAACCGCTGGTCCTGAGGAAG-3' and CRE2 5'-CTGAGGAAGAGGTGCTAAAGACCAAGGAGA TCTTCC-3'. Constructs were created that lacked CRE1 (phINS356m1LUC), CRE2 (phINS356m2LUC) and both CRE1 and CRE2 (phINS356m3LUC).

The mutations and integrity of final products were confirmed by DNA sequencing.

\section{Transfections}

Cells were grown to 80-90\% confluency, trypsinised and transferred to six-well plates at a density of $4 \times 10^{5}$ cells per well; $72 \mathrm{~h}$ later, the cells were transfected using Lipofectamine Plus reagent in a $1 \mathrm{ml}$ transfection cocktail containing $1 \mu \mathrm{g}$ plasmid DNA. Cells were incubated for $3 \mathrm{~h}$ in the transfection mixture and then overnight in $2 \mathrm{ml}$ of normal growth medium. The medium was then replaced with $2 \mathrm{ml}$ RPMI containing $1 \mathrm{mM}$ sodium pyruvate, $10 \mathrm{mM}$ Hepes balanced salt solution, $50 \mu \mathrm{M}$ $\beta$-mercaptoethanol, $3 \mathrm{mM}$ glucose and $10 \%$ foetal bovine serum, and the cells incubated for a further $24 \mathrm{~h}$. Cells were washed once with minimal medium before test substances or solvent alone were added to a final volume of $2 \mathrm{ml}$ per well. Unless specified, cells were incubated in minimal medium containing $11.1 \mathrm{mM}$ glucose with 
the test substances for $4 \mathrm{~h}$ at $37^{\circ} \mathrm{C}$ in a humidified atmosphere.

\section{Luciferase assays}

Cells were washed once with PBS and lysed with $400 \mu \mathrm{l}$ Passive Lysis Buffer (Promega). Cell lysis was carried out for 15 min with shaking and cell debris was removed by centrifugation at $13000 \mathrm{~g}$ for $5 \mathrm{~min}$. Then, $10 \mu \mathrm{l}$ cell extract were added to $350 \mu \mathrm{l}$ of A buffer $(15 \mathrm{mM}$ $\mathrm{MgSO}_{4} .7 \mathrm{H}_{2} \mathrm{O}, 30 \mathrm{mM}$ glycylglycine, $2 \mathrm{mM} \mathrm{Na} 2 \mathrm{ATP}$, $\mathrm{pH} 7 \cdot 8)$. To this, $150 \mu \mathrm{l}$ of $\mathrm{G}$ buffer $(30 \mathrm{mM}$ glycylglycine, $\mathrm{pH} 7.8$ ) containing $0.5 \mathrm{mM}$ luciferin were injected and the luminescence read at $560 \mathrm{~nm}$ using a Berthold Lumat LB 9501/16. Protein content was measured using the Bio-Rad DC Protein Assay (Bio-Rad) with BSA as a standard.

\section{Nuclear extracts}

Cells were grown to approximately $80 \%$ confluence in $9 \mathrm{~cm}$ Petri dishes and treated exactly as for luciferase assays. They were grown in complete RPMI 1640 medium containing $10 \%$ foetal bovine serum and $3 \mathrm{mM}$ glucose for $24 \mathrm{~h}$, then washed once with minimal medium before test substances or solvent alone were added. Cells were incubated in minimal medium containing $11.1 \mathrm{mM}$ glucose with the test substances for $4 \mathrm{~h}$ at $37^{\circ} \mathrm{C}$. Nuclear extracts were prepared by the method of Dignam et al. (1983) in the presence of protein phosphatase inhibitors (5 $\mathrm{mM} \beta$-glycerophosphate and $100 \mu \mathrm{M} \mathrm{Na} \mathrm{VO}_{4}$ ). The protein content was determined using the Bio-Rad DC Protein Assay with BSA as a standard.

\section{Electrophoretic mobility shift assays}

The coding sequences of the $30 \mathrm{bp}$ oligonucleotides of the human insulin gene CRE sites were: CRE1, 5'-TAAGA CTCTAATGACCCGCTGGTCCTGAGG-3'; CRE2, 5'-GGAAGAGGTGCTGACGACCAAGGAGATCTT-3'; CRE3, 5'-CCAGGACAGGCTGCATCAGAAGAGGC CATC-3'; CRE4, 5'-CCAAGGGCCTTTGCGTCAG GTGGGCTCAGG-3'. The double-stranded CRE oligonucleotides were labelled with T4 polynucleotide kinase (New England Biolabs, Hitchin, UK) and $\left[\gamma_{-}{ }^{32} \mathrm{P}\right] \mathrm{ATP}$ (Amersham), followed by purification using Quick Spin Columns (Roche). Nuclear binding assays were carried out in a total volume of $20 \mu \mathrm{l}$ of $20 \mathrm{mM}$ Hepes, $\mathrm{pH} 7 \cdot 9$, $70 \mathrm{mM} \mathrm{KCl}, 0.2 \mathrm{mM}$ EDTA, $0.5 \mathrm{mM}$ dithiothreitol and $10 \%$ glycerol. Nuclear extracts $(10 \mu \mathrm{g})$ were incubated on ice for $15 \mathrm{~min}$ with $1 \mu \mathrm{g}$ poly $(\mathrm{dI}-\mathrm{dC}) \cdot \operatorname{poly}(\mathrm{dI}-\mathrm{dC})$ as non-specific competitor along with other competitors or antibodies when indicated. Oligonucleotide competition binding assays were carried out with $300 \times$ molar excess of specific competing unlabelled CRE oligonucleotide. Antibody competition assays had the addition of either

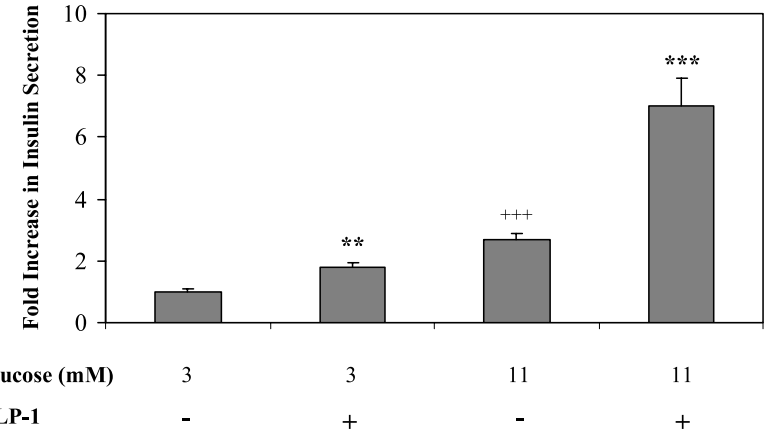

Figure 1 Response of INS-1 $\beta$-cells to glucose and GLP-1. INS-1 cells were incubated for $24 \mathrm{~h}$ in medium containing $3 \mathrm{mM}$ glucose and foetal bovine serum. The cells were then pre-incubated in Hepes-balanced buffer containing $3 \mathrm{mM}$ glucose with $0 \cdot 2 \%$ BSA for $1 \mathrm{~h}$ followed by stimulation for $45 \mathrm{~min}$ in Hepes-balanced buffer containing either 3 or $11 \cdot 1 \mathrm{mM}$ glucose in the presence or absence of $10 \mathrm{nM}$ GLP-1. The levels of insulin secreted were measured by radioimmunoassay. The data represent the means \pm S.E.M. of three independent experiments carried out in triplicate and are expressed as fold increases in insulin secretion compared with $3 \mathrm{mM}$ glucose. Statistical analyses of increases in insulin secretion, which were relevant to specific assays, were calculated. Cells without GLP-1: 11·1 mM glucose compared with $3 \mathrm{mM}$ glucose, ${ }^{++} P<0 \cdot 001$. GLP-1 treated cells: comparison with the same concentration of glucose without GLP-1, ${ }^{*} P<0 \cdot 01$, ${ }^{* * *} P<0 \cdot 001$.

$1 \mu \mathrm{l}$ rabbit polyclonal anti-human pancreatic duodenal homeobox-1 (PDX-1) serum (a gift from Dr C. Wright, Vanderbilt University Medical Center, Nashville, TN, USA) or $1 \mu \mathrm{l}$ rabbit serum as a control. Labelled oligonucleotide corresponding to $60 \mathrm{fmol}$ was added and incubation was carried out at room temperature for $30 \mathrm{~min}$. The reaction products were resolved on $6 \%$ nondenaturing polyacrylamide gels run in TGE buffer, $\mathrm{pH} 8.5(50 \mathrm{mM}$ Tris, $380 \mathrm{mM}$ glycine, $2 \mathrm{mM}$ EDTA). The gels were dried and subjected to autoradiography at $-70^{\circ} \mathrm{C}$.

\section{Statistical analysis}

Statistical analysis was performed using a Blackwell Science statistical package (Blackwell Scientific Publications, Oxford, UK) and statistical significance was measured by analysis of variance.

\section{Results}

Effect of GLP-1 on human insulin promoter activity

GLP-1 is known to potentiate the effects of glucose on insulin secretion and gene expression. In preliminary experiments the responsiveness of INS-1 $\beta$-cells to glucose and GLP-1 was investigated (Fig. 1). INS-1 cells responded to glucose with a significant $2 \cdot 5$-fold increase in insulin secretion when cultured in the presence of $11 \cdot 1 \mathrm{mM}$ compared with $3 \mathrm{mM}$ glucose. Treatment with 


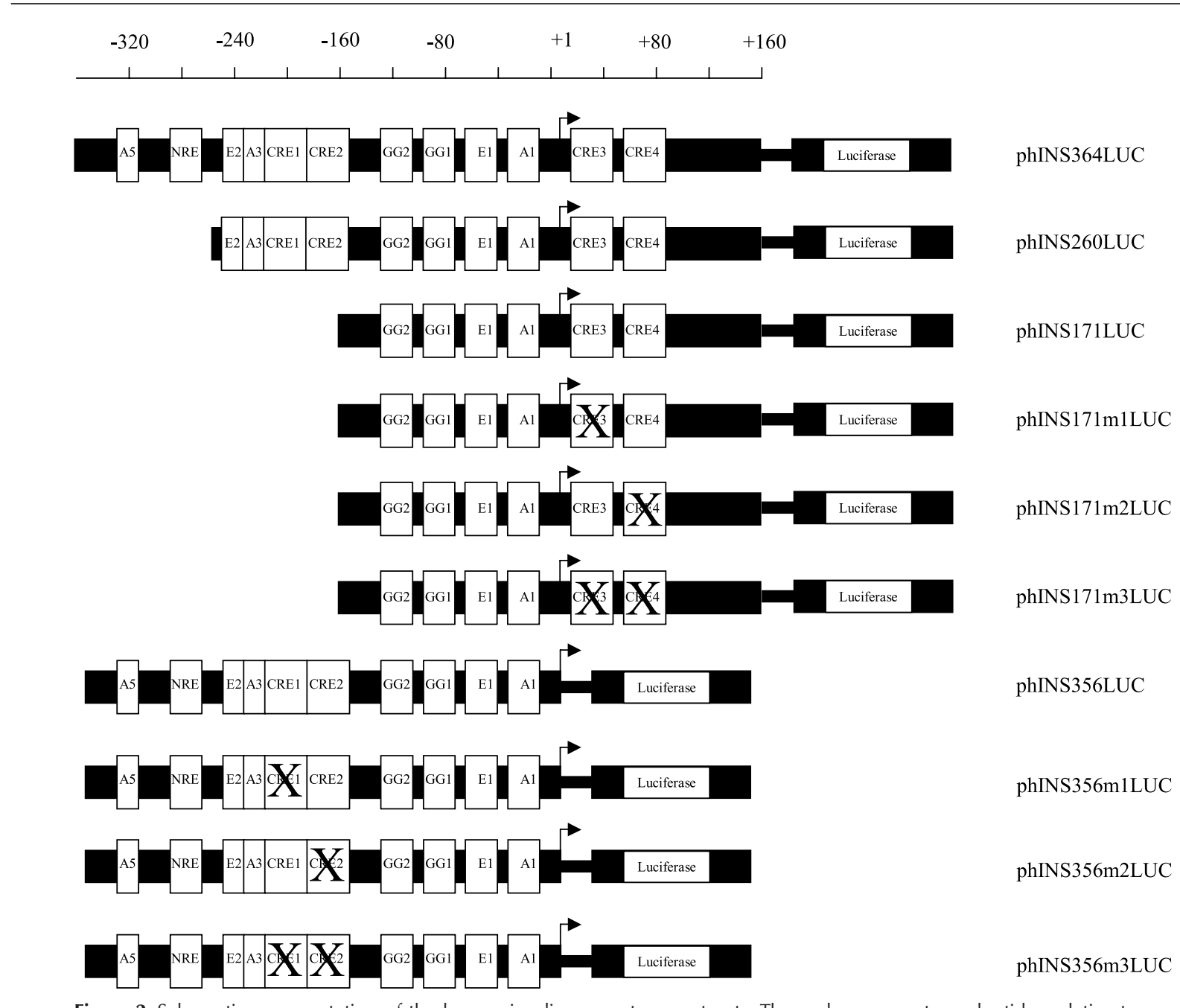

Figure 2 Schematic representation of the human insulin promoter constructs. The scale represents nucleotides relative to the transcription start site +1 and forward arrow. The positions of the four CREs and major cis-acting elements are indicated.

$10 \mathrm{nM}$ GLP-1 resulted in significant increases in insulin secretion in both 3 and $11.1 \mathrm{mM}$ glucose. Insulin secretion increased 1.4-fold in the presence of GLP-1 in cells cultured in $3 \mathrm{mM}$ glucose compared with $3 \mathrm{mM}$ glucose alone and by $2 \cdot 7$-fold in cells cultured in GLP-1 and $11 \mathrm{mM}$ glucose compared with $11 \mathrm{mM}$ glucose alone. In addition, Northern blot analysis showed that the GLP-1stimulated increase in insulin secretion was accompanied by 1.7 -fold $(P<0 \cdot 001)$ and 1.5 -fold $(P<0 \cdot 05)$ increases in the amount of preproinsulin mRNA in low and high glucose respectively (data not shown). Thus, INS-1 $\beta$-cells respond to GLP-1 by increasing insulin secretion in a glucose-dependent manner and were used for all further studies.

More detailed studies on the mechanism of GLP-1 stimulation of the insulin promoter were carried out using luciferase reporter constructs containing the rat insulin I promoter (pFOXLUC410) and a series of human insulin promoter constructs (Fig. 2). Initial experiments using pFOXLUC410, which contained the rat insulin I promoter $(-410$ to $+1 \mathrm{bp})$ in the pFOXLUC vector, showed that GLP-1 stimulated the activity of the rat insulin I promoter both in $3 \mathrm{mM}$ glucose (2-fold increase) and in $11.1 \mathrm{mM}$ glucose $(2 \cdot 4$-fold increase) (Fig. 3). The magnitude of this effect on the rat insulin promoter was in keeping with previous studies using a similar rat insulin promoter construct in INS-1 cells (Skoglund et al. 2000, Kemp \& Habener 2001, Chepurny et al. 2002). In detailed dose-response experiments (data not shown), a maximal effect of GLP-1 was observed at $10 \mathrm{nM}$ and this concentration was used in all further experiments. The human insulin promoter contains an inhibitory element between -279 and -258 (Boam et al. 1990) and regulatory sequences that lie downstream of the transcription start site (Inada et al. 1999). When the human insulin promoter construct phINS364LUC (Fig. 2), which contains the 


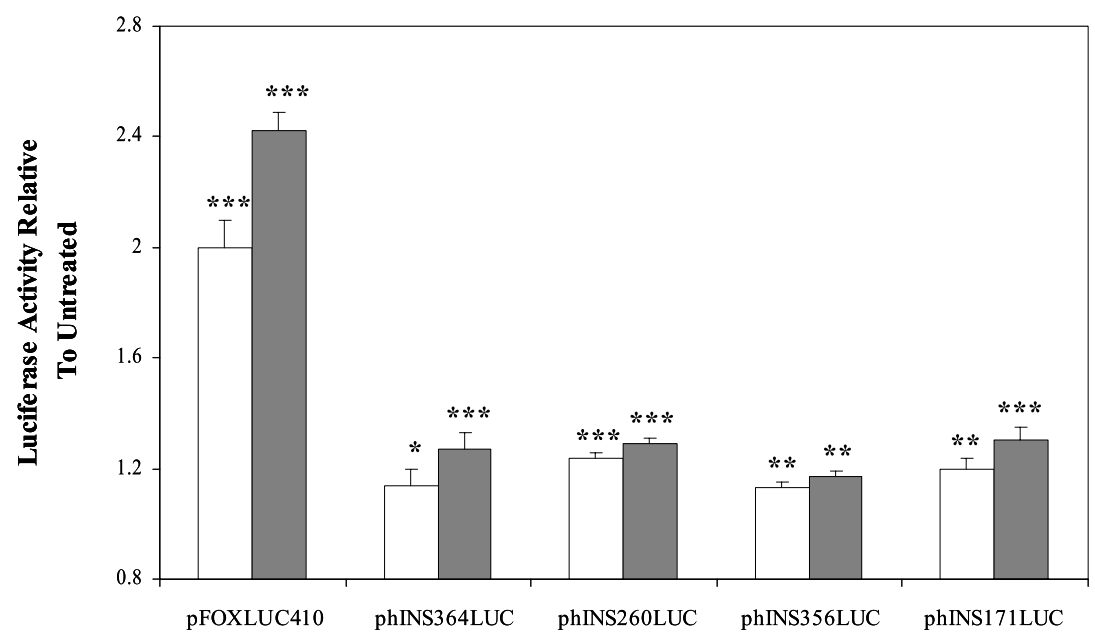

Figure 3 Effect of GLP-1 on rat 1 and human insulin promoter constructs in INS-1 cells. INS- 1 cells were transfected with $1 \mu \mathrm{g}$ of the indicated plasmids. Construct pFOXLUC410 contained the rat insulin I promoter $(-410$ to $+1 \mathrm{bp})$ in the pFOXLUC vector and the various human insulin promoter constructs are outlined in Fig. 2. Cells were cultured for $24 \mathrm{~h}$ in medium containing low glucose $(3 \mathrm{mM})$ and foetal bovine serum, after which the cells were washed once with serum-free medium and cultured in serum-free medium containing 3 or $11 \cdot 1 \mathrm{mM}$ glucose in the presence or absence of $10 \mathrm{nM} \mathrm{GLP}-1$ for $4 \mathrm{~h}$. Whole-cell extracts were then prepared and firefly luciferase activity measured. The results are presented as luciferase activity in cells incubated in GLP-1 relative to those incubated in $3 \mathrm{mM}$ (open bars) or $11 \cdot 1 \mathrm{mM}$ glucose (shaded bars) in the absence of GLP-1. The data represent the means \pm S.E.M. of four independent experiments carried out in triplicate and the significance of GLP-1 stimulation was determined. ${ }^{*} P<0 \cdot 05,{ }^{*} P<0 \cdot 01$, ${ }^{* * *} P<0 \cdot 001$.

inhibitory and downstream elements, was used, there was a significant stimulation by GLP-1 of promoter activity in $3 \mathrm{mM}$ glucose (1.12-fold increase) and $11 \cdot 1 \mathrm{mM}$ glucose (1.25-fold increase) (Fig. 3). GLP-1 also stimulated the activity of the human insulin promoter construct phINS260LUC (Fig. 2), which lacked the inhibitory element (1.23- and $1 \cdot 27$-fold in 3 and $11 \mathrm{mM}$ glucose respectively) (Fig. 3). The inhibitory element, which also functions as a glucose response element in transfected islets (Sander et al. 1998), does not therefore appear to affect the responsiveness of the insulin promoter to GLP-1. In general the human insulin promoter constructs were much less responsive to GLP-1 than the rat insulin promoter (Fig. 3). There was no effect of glucose or GLP-1 on the control vectors pFOXLUC or pGL3 (data not shown).

\section{Role of CREs in regulating the human insulin promoter}

Further experiments were designed to determine whether CREs within the human insulin promoter might be involved in mediating the effects of GLP-1. There are four CREs within the human insulin promoter located at -210 (CRE1, TGACCCGC), - 183 (CRE2, TGACG ACC), +18 (CRE3, TGCATCAG) and in the first intron at +61 (CRE4, TGCGTCAG) (Fig. 2). CRE2 is the only one conserved between humans and rodents (Philippe
\& Missotten 1990, Inagaki et al. 1992). The absence of sequences that included CRE1 and CRE2 in phINS171LUC, and CRE3 and CRE4 in phINS356LUC did not diminish the effect of GLP-1 on promoter activity (Fig. 3). This suggests that CREs that lie upstream and downstream of the transcription start site might be involved.

The individual roles of CRE1 and CRE2 were studied by mutating these responsive elements in the construct phINS356LUC as outlined in Fig. 2. Similarly, the roles of CRE3 and CRE4 were investigated by creating a series of mutations in the construct phINS171LUC (Fig. 2). In order to determine if all four CRE sites were transcriptionally active, initial experiments looked at the effect of the mutations on the rates of basal transcription. Mutagenesis of CRE1 (phINS356m1LUC) and of CRE2 (phINS356m2LUC) resulted in a reduction of basal transcription to 0.63 and 0.65 relative to the unmutated construct respectively (Fig. 4A). Construct phINS356m3LUC, in which both CRE1 and CRE2 were mutated, displayed an even greater reduction in basal transcription to $0 \cdot 4$ relative to the unmutated construct (Fig. 4A). Mutagenesis of CRE3 (phINS171m1LUC), of CRE4 (phINS171m2LUC) and of both CRE3 and CRE4 (phINS171m3LUC) also led to reductions in basal transcription to $0.70,0.58$ and 0.66 relative to the unmutated construct respectively (Fig. 4B). These data 
A

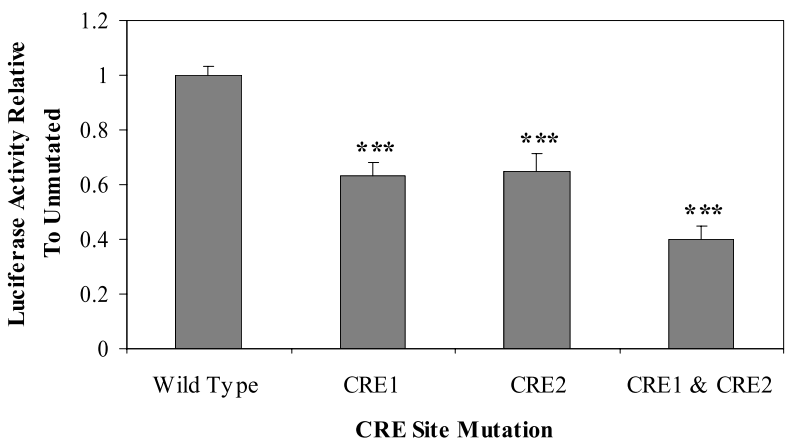

B

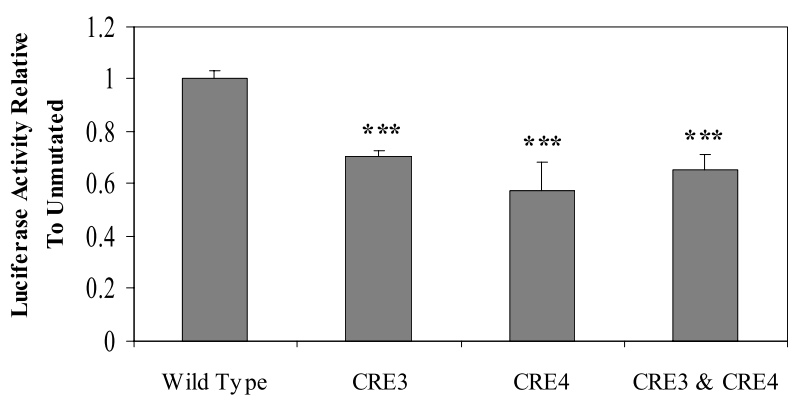

CRE Site Mutation

Figure 4 Effect of CRE mutations on basal transcription rates. INS-1 cells that had been transfected with appropriate plasmids were cultured for $24 \mathrm{~h}$ in medium containing low glucose $(3 \mathrm{mM})$ and foetal bovine serum. Following this, the cells were washed once with serum-free medium and incubated for $4 \mathrm{~h}$ in serum-free medium containing $11 \cdot 1 \mathrm{mM}$ glucose. Whole-cell extracts were then prepared and firefly luciferase activity measured. The results are presented as luciferase activity relative to that in cells transfected with plasmids containing wild-type CRE sites. (A) phINS356LUC series of constructs. (B) phINS171LUC series of constructs. The data represent the means \pm S.E.M. of three independent experiments carried out in triplicate and the significance of reductions in transcriptional activity was determined. ${ }^{* *} P<0 \cdot 001$.

show that all four CRE sites in the human insulin promoter are transcriptionally active and that there could be constitutive cAMP/PKA activity in INS-1 cells.

Role of individual CREs in the human insulin promoter response to GLP-1

Both constructs phINS356LUC and phINS171LUC showed significant stimulation by GLP-1 (Fig. 5). Mutagenesis of CRE1 (phINS356m1LUC) had no effect on GLP-1 stimulation while mutagenesis of CRE2 (phINS356m2LUC) completely abolished the stimulatory effect of GLP-1 (Fig. 5A). In keeping with these results,
A

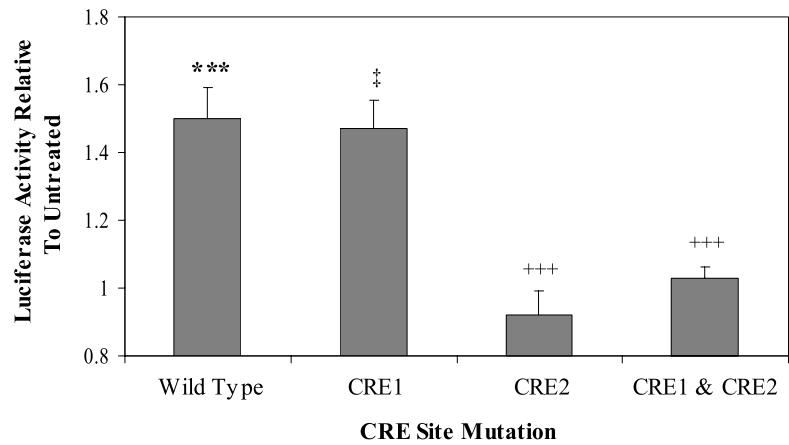

$\mathrm{B}$

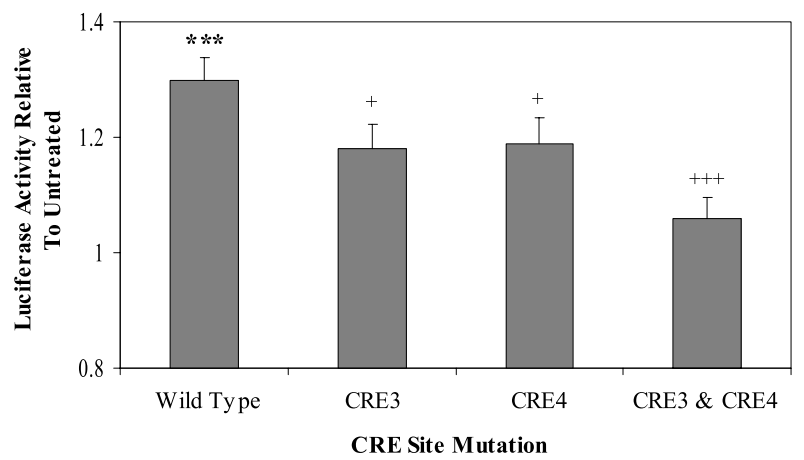

Figure 5 Response of CRE sites to GLP-1. INS-1 cells were transfected with plasmids containing wild-type or mutated CRE sites as indicated. Cells were cultured for $24 \mathrm{~h}$ in medium containing low glucose ( $3 \mathrm{mM})$ and foetal bovine serum, after which the cells were washed once with serum-free medium and cultured in serum-free medium containing $11 \cdot 1 \mathrm{mM}$ glucose in the presence or absence of $10 \mathrm{nM} \mathrm{GLP}-1$ for $4 \mathrm{~h}$. Whole-cell extracts were then prepared and firefly luciferase activity measured. The results are presented as luciferase activity in cells incubated in GLP-1 relative to those transfected with the same plasmid incubated in the absence of GLP-1. (A) Effect of GLP-1 on phINS356LUC series of constructs. (B) Effect of GLP-1 on phINS171LUC series of constructs. The data represent the means \pm S.E.M. of three independent experiments carried out in triplicate. Statistical analyses, which were relevant to specific assays, were calculated. Wild type: the significance of GLP-1 stimulation, ${ }^{* *} P<0 \cdot 001$. CRE1: the significance of no reduction in GLP-1 stimulation in the construct with a mutated CRE1 site compared with wild type, ${ }^{\ddagger} P<0 \cdot 05$. All other constructs: the significance of reduction in GLP-1 stimulation in constructs with mutated CREs compared with wild type, ${ }^{+} P<0 \cdot 05,{ }^{+++} P<0 \cdot 001$.

the construct, in which both CRE1 and CRE2 were mutated (phINS356m3LUC), was also unresponsive to GLP-1 (Fig. 5A). Mutagenesis of CRE3 (phINS171m1LUC) and of CRE4 (phINS171m2LUC) diminished the stimulatory effect of GLP-1 from a 1.30fold increase for the unmutated construct to 1.18- and 1-19-fold increases respectively (Fig. 5B), while the 
construct phINS171m3LUC, in which both CRE3 and CRE4 were mutated, completely blocked the effects of GLP-1 (Fig. 5B). This would suggest that CRE3 and CRE4 act in a cumulative manner. In summary, the stimulatory effect of GLP-1 on the human insulin promoter is mediated through CRE2, CRE3 and CRE4, while CRE1 is not involved.

The response of individual CREs in the human insulin promoter to forskolin

GLP-1 is thought to act primarily through a G-proteincoupled receptor leading to increased intracellular cAMP levels (Thorens 1992). The responsiveness of the different CRE sites to cAMP was investigated using forskolin, a stimulator of adenylate cyclase. Although forskolin raises cAMP levels in an unphysiological manner and cannot be used in a qualitative manner, it is widely recognised that increased intracellular levels of cAMP can mimic signalling pathways. Both constructs phINS356LUC and phINS171LUC showed stimulation upon treatment with forskolin (Fig. 6). The contribution of CRE1 and CRE2 sites to forskolin responsiveness was investigated using the phINS356LUC mutant constructs. Loss of CRE2 resulted in a concomitant loss of responsiveness to forskolin, while mutation of CRE1 had only a minor effect (Fig. 6A). Mutagenesis of CRE3 and CRE4 had minimal effect on forskolin stimulation on phINS171LUC, however the double mutation of CRE3 and CRE4 did result in a significant reduction in stimulation (Fig. 6B). The inability of the CRE3 and CRE4 mutations to significantly diminish forskolin effects may reflect the promiscuity of binding specificities for the eight or so members of the bZIP family of transcription factors that are known to recognise CRE-related sequences. It is highly significant, however, that whereas the CRE3 and CRE4 mutations only weakly inhibited forskolin stimulation, they produced significant reductions in the stimulatory effect of GLP-1 as described above. This would suggest that GLP-1 is acting on CRE3 and CRE4 mainly by a mechanism other than through an increase in active cAMP-dependent transcription factors.

The role of cAMP in GLP-1 stimulation of the human insulin promoter was further examined by using $\mathrm{H}-89$, the inhibitor of protein kinase A (PKA). While H-89 $(10 \mu \mathrm{M})$ completely abolished the stimulatory effect of forskolin on the phINS260LUC construct $(P<0.01)$, it only partially inhibited the stimulatory effect of GLP-1 on phINS260LUC construct by $48 \%(P<0 \cdot 01)$ and $39 \%$ $(P<0 \cdot 001)$ in 3 and $11 \cdot 1 \mathrm{mM}$ glucose respectively (data not shown), lending further support to the view that GLP-1 can act through cAMP-dependent and noncAMP-dependent intracellular pathways. These findings are in keeping with the observations that H-89 is ineffective in blocking GLP-1 stimulation of the rat insulin I promoter (Skoglund et al. 2000).
A

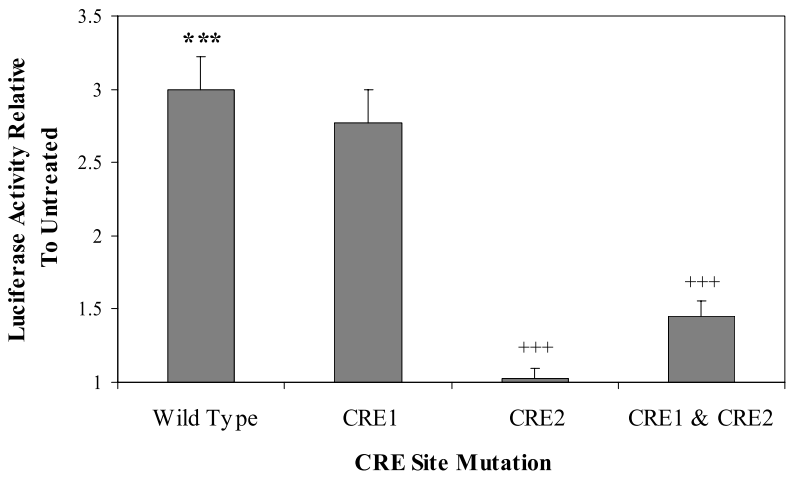

B

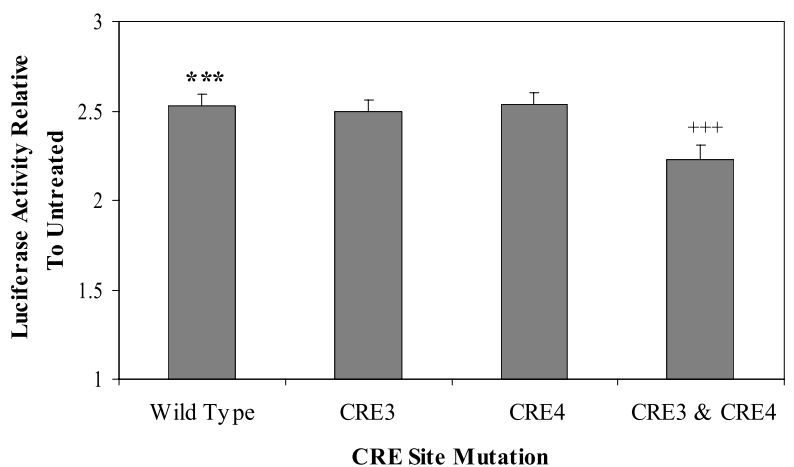

Figure 6 Response of CRE sites to forskolin. INS-1 cells were transfected with plasmids containing wild-type or mutated CRE sites as indicated. Cells were cultured for $24 \mathrm{~h}$ in medium containing low glucose $(3 \mathrm{mM})$ and foetal bovine serum, after which the cells were washed once with serum-free medium and cultured in serum-free medium containing $11.1 \mathrm{mM}$ glucose in the presence or absence of forskolin $(10 \mu \mathrm{M})$ for $4 \mathrm{~h}$. Whole-cell extracts were then prepared and firefly luciferase activity measured. The results are presented as luciferase activity in cells incubated in forskolin relative to cells transfected with the same plasmid incubated in the absence of forskolin. (A) Effect of forskolin on phINS356LUC series of constructs. (B) Effect of forskolin on phINS171LUC series of constructs. The data represent the means \pm S.E.M. Of three independent experiments carried out in triplicate. Statistical analyses, which were relevant to specific assays, were calculated. Wild type: the significance of forskolin stimulation, ${ }^{* *} P<0 \cdot 001$. All other constructs: the significance of reduction in forskolin stimulation in constructs with mutated CREs compared with wild type, ${ }^{+++} P<0 \cdot 001$.

\section{Nuclear protein binding to individual CRE sites}

Nuclear proteins were purified from INS-1 cells that had been grown in $3 \mathrm{mM}$ glucose for $24 \mathrm{~h}$ followed by $4 \mathrm{~h}$ in minimal medium containing $11 \cdot 1 \mathrm{mM}$ glucose. When the proteins were incubated with labelled oligonucleotides containing each of the four human insulin promoter CRE sites and analysed by electrophoretic mobility shift assay, multiple retarded bands were observed. Unique patterns of 


\section{$\mathbf{A}$}

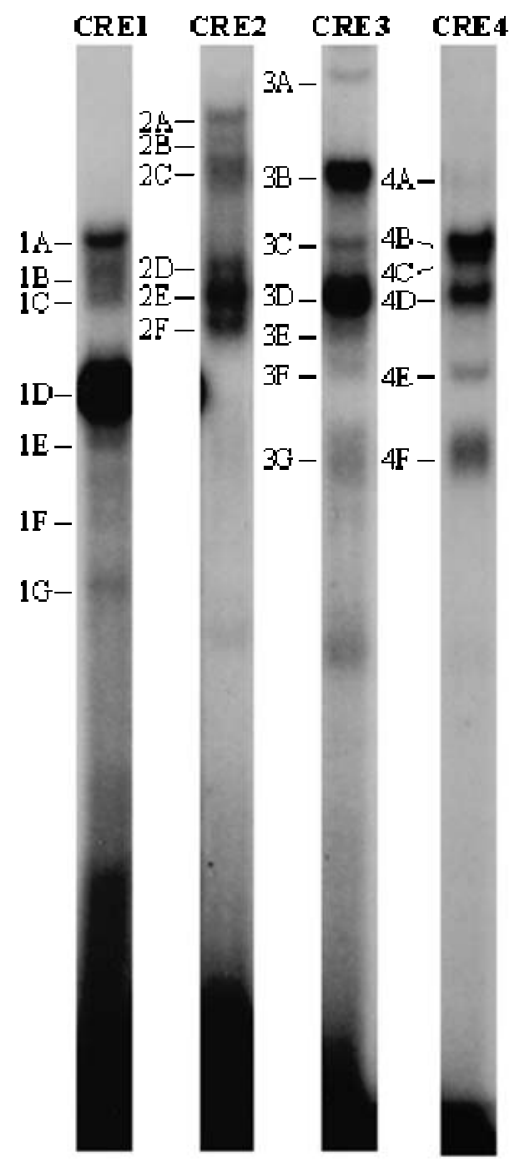

B

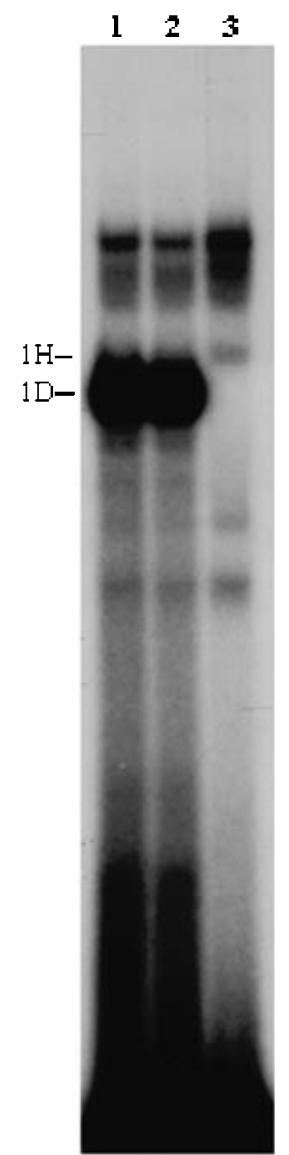

Figure 7 Nuclear protein binding to CRE sites. Nuclear extracts from INS-1 cells that had been incubated for $24 \mathrm{~h}$ in $3 \mathrm{mM}$ glucose followed by $4 \mathrm{~h}$ in medium containing $11 \cdot 1 \mathrm{mM}$ glucose were incubated with labelled oligonucleotides containing the human insulin promoter CRE sites and resolved by electrophoretic mobility shift analysis. Specific DNA-protein complexes are indicated with arbitrary labels. (A) Nuclear extract was incubated with the labelled CRE oligonucleotide indicated above the lane. The different samples were run on adjacent lanes in the same gel. (B) Labelled CRE1 oligonucleotide was incubated with nuclear extract that had either received no additional treatment (lane 1), been pre-incubated for 15 min on ice with rabbit serum (lane 2) or pre-incubated for 15 min on ice with rabbit polyclonal anti-human PDX-1 serum (lane 3).

protein binding were formed with each CRE site and the various DNA-protein complexes have been assigned arbitrary names (Fig. 7A). Each CRE displayed one or two major bands including (1A and $1 \mathrm{D}, 2 \mathrm{E}, 3 \mathrm{~B}$ and $3 \mathrm{D}$, and $4 \mathrm{~B}$ and $4 \mathrm{D})$ and a number of minor bands. Antibody competition studies showed the major complex 1D contained PDX-1 (Fig. 7B) and removal of PDX-1 permitted another protein to bind and form the complex $1 \mathrm{H}$. Clearly, the presence of the overlapping PDX-1 binding site affects the binding of proteins and possibly the activity of the CRE1 site. Many complexes were common to several CRE sites. For example, bands corresponding to the CRE1 complex 1A were also observed with CRE3 and CRE4 (3C and 4B respectively). The major band in the CRE2 lane (2E) was present in all the other lanes as 1C, 3D and 4D, while one of the two major complexes created with CRE3 (3B) had analogous forms with CRE2 (2C) and CRE4 (4A). It is important to note, however, that although some proteins could bind to different CRE sites, the relative degree of binding was often completely different. Significantly, all four CREs also bound proteins that were unique for a particular site. The CRE2 lane had two unique minor bands (2A and $2 \mathrm{~B}$ ) that represented high molecular weight DNA-proteins. The unique CRE3 complex $3 \mathrm{~A}$ also bound a high molecular weight protein and CRE4 had the unique minor complex, 4C. The 


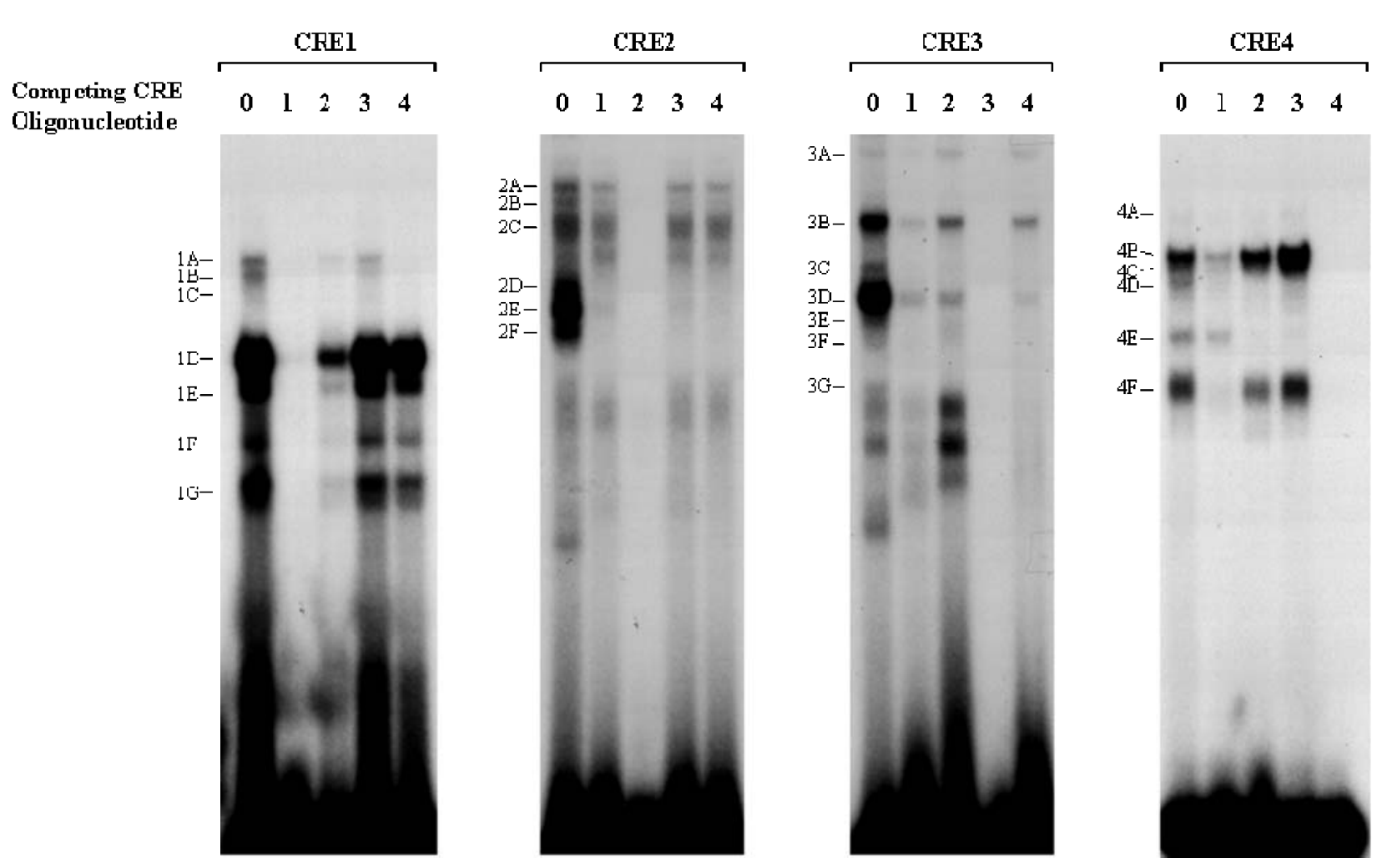

Figure 8 Competition experiments show shared properties of CRE sites. Nuclear extracts from INS-1 cells that had been incubated for $24 \mathrm{~h}$ in $3 \mathrm{mM}$ glucose followed by $4 \mathrm{~h}$ in medium containing $11 \cdot 1 \mathrm{mM}$ glucose were incubated with labelled oligonucleotides containing the human insulin promoter CRE indicated above each gel. DNA-protein complexes were resolved by electrophoretic mobility shift analysis and the complexes were labelled as in Fig. 7. Competing CRE oligonucleotides were added at a 300 -fold molar excess 15 min prior to the addition of the labelled CRE oligonucleotide. The identity of the competing CRE oligonucleotide is shown above each lane with ' 0 ' representing the absence of any competing oligonucleotide.

DNA-protein complexes and their relative binding to the different CREs were consistently observed with four different nuclear protein preparations. Taken together, these results demonstrate that, while the four CRE sites in the human insulin promoter share some common characteristics, they are distinct from each other.

In order to understand better the shared characteristics of the four CRE sites, competition studies were performed, in which the nuclear assays were preincubated with specific competing CRE oligonucleotides (Fig. 8). Formation of the CRE1 complex 1D, and to a lesser degree 1E, was reduced by the CRE2 oligonucleotide, but unaffected by the oligonucleotides for CRE3 and CRE4. Reduced complex 1D assembly suggests that the CRE2 site may have some affinity for PDX-1. The CRE4 oligonucleotide completely abolished the creation of complexes $1 \mathrm{~A}, 1 \mathrm{~B}$ and $1 \mathrm{C}$ while the other $\mathrm{CRE}$ oligonucleotides reduced their formation. In keeping with the observation from Fig. 7A that the major CRE2 complex (2E) is common to all CRE sites, its formation, along with that of $2 \mathrm{D}$ and $2 \mathrm{~F}$, was completely prevented by all four CRE oligonucleotides. On the other hand, the high molecular weight complexes $2 \mathrm{~A}, 2 \mathrm{~B}$ and $2 \mathrm{C}$ were unaffected by the presence of any of the other CRE oligonucleotides. The main CRE3 complexes 3B and 3D were less evident when other CRE oligonucleotides were present, however only the self-competing oligonucleotide completely prevented their creation, suggesting that the proteins in question bind preferentially to CRE3. The major CRE4 complexes $4 \mathrm{~B}$ and $4 \mathrm{~F}$ were partly reduced by CRE1 but not by the other CRE oligonucleotides with the CRE3 oligonucleotide increasing formation of complexes $4 \mathrm{~B}$ and $4 \mathrm{C}$. This could be due to CRE3 sequestering competing proteins that bind to CRE4, e.g. those in the complexes 4D and 4E. It is evident from these competition studies that the binding of nuclear proteins to the four human insulin promoters is a complex and dynamic process.

\section{Action of GLP-1 and forskolin on the individual CRE sites}

Potential variations in transcription factor binding at the individual CRE sites during stimulation by GLP-1 and forskolin were explored by performing binding assays with nuclear extracts from INS-1 cells that had been treated 


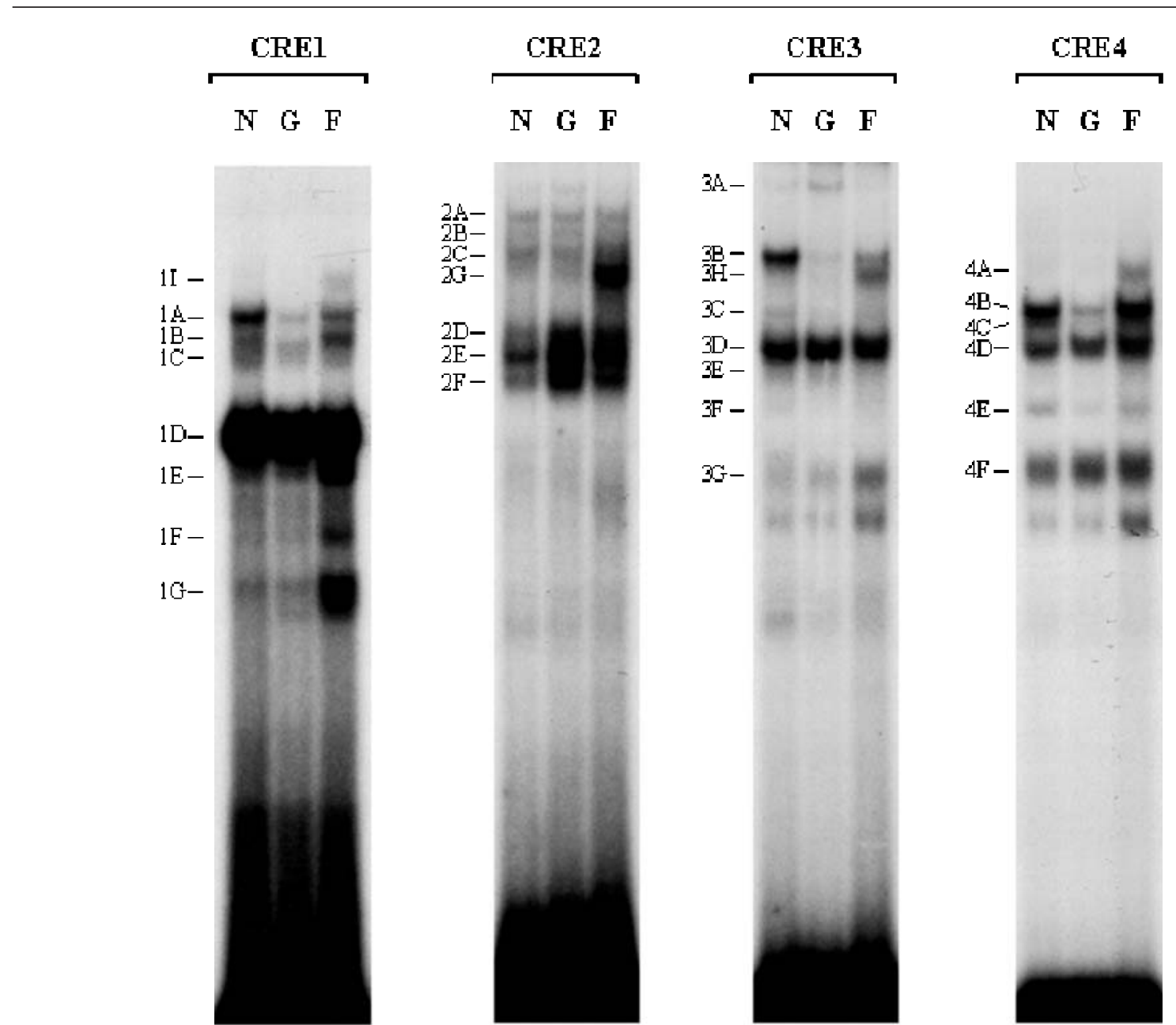

Figure 9 Effect of GLP-1 and forskolin on proteins binding to individual CRE sites. Labelled oligonucleotides containing the human insulin promoter CRE indicated above each gel were incubated with nuclear extracts from INS-1 cells that had been cultured in medium containing low glucose ( $3 \mathrm{mM})$ and foetal bovine serum for $24 \mathrm{~h}$, followed by washing with serum-free medium and cultured for $4 \mathrm{~h}$ in serum-free $11.1 \mathrm{mM}$ glucose medium. During incubation in $11.1 \mathrm{mM}$ glucose, the cells either received no treatment (lane N), were incubated in the presence of $10 \mathrm{nM} \mathrm{GLP}-1$ (lane G) or were incubated in the presence of $10 \mu \mathrm{M}$ forskolin (lane F). DNA-protein complexes were resolved by electrophoretic mobility shift analysis and are marked as above.

with either GLP-1 or forskolin (Fig. 9). For CRE-1, GLP-1 had no effect on the binding of PDX-1 (1D), whereas the major complex $1 \mathrm{~A}$ and minor complexes $1 \mathrm{~B}$ and $1 \mathrm{C}$ were reduced. Forskolin, on the other hand, led to increased levels of $1 \mathrm{~B}, 1 \mathrm{E}$ and $1 \mathrm{G}$ along with low levels of a new complex (1I) being produced. The CRE2 site revealed dramatic changes upon treatment with GLP-1 and forskolin. In both cases, the major complex of $2 \mathrm{E}$, and the minor complexes $2 \mathrm{D}$ and $2 \mathrm{~F}$, were greatly increased, especially with GLP-1. Forskolin, but not GLP-1, also gave rise to a new highly abundant complex (2 G). In marked contrast to CRE2, the effect of GLP-1 on CRE3 was the virtual total loss of a major complex, namely $3 \mathrm{~B}$. Interestingly, the competition nuclear binding studies showed that the protein in $3 \mathrm{~B}$ bound more strongly to CRE3 than to the other CREs so this regulatory pathway may be unique to CRE3. Treatment with forskolin led to a less striking reduction of this complex along with the creation of a new one $(3 \mathrm{H})$. In a manner similar to CRE3, GLP-1 caused the noticeable loss of a major and a minor CRE4 complex with the levels of $4 \mathrm{~B}$ and $4 \mathrm{C}$ being greatly diminished. Forskolin had no effect on these complexes and increased appreciably the amount of complex 4A. Collectively, these findings show that GLP-1 and forskolin can upregulate transcription through the actions of both identical and different DNA-binding proteins, and that the individual CRE sites of the human insulin promoter respond by diverse mechanisms. 


\section{Discussion}

A major finding of this study was that GLP-1 stimulates the activity of the human insulin promoter and that this effect is mediated through CRE2, CRE3 and CRE4 while CRE1 does not participate. The use of forskolin to raise intracellular cAMP levels suggested that CRE2, CRE3 and CRE4 function as CREs but that CRE1 does not. The most likely explanation for this latter observation is that the binding of PDX-1 at the overlapping A3 site results in CRE1 being permanently occupied, thereby preventing other transcription factors from binding. Another major finding of this study was that, although the four CREs of the human insulin promoter share some nuclear protein-binding properties (Inagaki et al. 1992, Inada et al. 1999), each CRE site is unique. In addition, the CRE sites involved in stimulation by GLP-1 and forskolin do so by different mechanisms. Changes in DNA-protein complex formation brought about by raised levels of cAMP through administration of forskolin were most obvious at CRE2 where large increases in several complexes were observed. Furthermore, all of the proteins responsible for GLP-1 stimulation at CRE2 were the same as those involved in the cAMP response. These findings strongly suggest that GLP-1 stimulates CRE2 through the cAMP signalling pathways. Further studies are underway to identify the proteins involved: potential candidates being CRE-binding protein (CREB), CRE modulator (CREM), activating transcription factor-1 (ATF-1) or other PKA- and cAMP-associated factors. Preliminary results using CRE2 oligonucleotide trapping along with Western blotting show that the transcription factor ATF-2 appears to bind preferentially in comparison with CREB-1.

CRE3 and CRE4, on the other hand, appear to respond to GLP-1 in an alternative manner. At these CREs, GLP-1 stimulation is accompanied by a large reduction in prominent DNA-protein complexes while forskolin stimulation elicits a different set of changes in banding patterns. Together, these observations suggest that GLP-1 stimulates CRE3 and CRE4 by pathways other than those involving PKA and cAMP. This would explain why the mutations at these two CREs could greatly diminish the GLP-1 response in reporter assays while being ineffective against forskolin stimulation. The complexes that were reduced by GLP-1 stimulation could contain repressor proteins that either elicit their response directly or through other assembled proteins, e.g. inducible cAMP early repressor (ICER) or CREM variants (Inada et al. 1999).

Our observations that the GLP-1 response may embrace pathways other than those involving PKA and cAMP, and the large variety of proteins seen to bind to the different CREs suggest that many proteins may be involved, including an unidentified bZIP transcription factor. A similar situation occurs in the rat insulin I promoter where an unidentified bZIP protein binds to the single CRE centred around -183 (Philippe \& Missotten 1990,
Chepurny et al. 2002). Further support comes from the findings that GLP-1 can stimulate rat insulin I gene transcription in INS-1 cells in a CREB-, CREM- and ATF-1-independent manner (Kemp \& Habener 2001).

Comparison of the insulin gene sequences in the Old World monkeys of chimpanzee and African green monkey (Seino et al. 1992), which diverged from humans about 5 and 25 million years ago respectively (Vincent et al. 2003), shows remarkable similarity with the human insulin promoter. The four CRE sites are highly conserved in the Old World monkeys with the chimpanzee CREs having identical sequences to the human forms and the African green monkey CREs differing by only the first base in CRE4. These sequences are less well conserved in the New World owl monkey (Seino et al. 1987), which diverged from humans about 35 million years ago (Seino et al. 1992), with it lacking CRE1 (the shared A3 element being present) and CRE4. Pigs and rats diverged from humans 65 and 75 million years ago respectively (Hedges \& Kumar 2003) and their insulin genes (Han \& Tuch 2001) have a single conserved CRE equivalent to CRE2. Taken together, the presence of additional CRE sites in the human insulin promoter may reflect evolutionary changes in response to different physiological demands associated with diet. While the diet of omnivorous pigs and rodents would consist mainly of complex carbohydrates, oils and protein, only primates consume large amounts of fruit and, therefore, have to deal with large quantities of sugar.

We also show here that the human insulin promoter was much less responsive to GLP-1 than the rat insulin I promoter. This may be a physiologically significant observation that reflects subtle differences in the organisation and regulation of cis-acting elements in the insulin promoters from different species (Clark \& Docherty 1992, Melloul et al. 2002). The reduced responsiveness may also reflect the difficulties in studying the human insulin promoter in rodent cell lines. There are no available human $\beta$-cell lines. NES2Y, a human $\beta$-cell-like line derived from a patient with persistent hypoinsulinaemic hyperglycaemia of infancy, that was used in our previous studies (Macfarlane et al. 1997), stopped expressing insulin beyond about passage eight, the lowest passage now available. This cell is therefore of limited use for this or related studies on the human insulin promoter. On the other hand, the reliance on rodent $\beta$-cell lines may not be a significant problem as evidenced by the fact that the human insulin promoter functions well in rodent cells. It will drive $\beta$-cell-specific expression in transgenic mice (Itier et al. 1996) and previous studies on the mapping of regulatory elements in the human insulin gene have utilised available rodent (and hamster) $\beta$-cell lines (Boam et al. 1990, Tomonari et al. 1996). On balance therefore it is likely that the human insulin promoter is less responsive to GLP-1.

GLP-1 and its long-lasting analogues may have a role in the treatment of type 2 diabetes. Thus subcutaneous 
administration of GLP-1 increased insulin secretion, inhibited gastric emptying and lowered glucagon levels in type 2 diabetic patients (Willms et al. 1996). It has the further therapeutic advantage that its administration is associated with low incidence of hypoglycaemia without any risk of weight gain (Zander et al. 2002, Knop et al. 2003). If GLP-1 is to find use as a therapeutic agent in the treatment of type 2 diabetes, then more data are required on exactly how GLP-1 regulates expression of the human gene. Most of the previous studies have focused on rodent insulin genes. The present study represents the first to document GLP-1 responsive sequences within the human insulin gene and is, therefore, of relevance to enable a better understanding of how GLP-1 mediates its effects on glucose homeostasis in people with diabetes.

\section{Funding}

Supported by the Wellcome Trust. E M S was the recipient of a Medical Research Council CASE studentship awarded to GlaxoSmithKline. The authors declare that there is no conflict of interest that would prejudice the impartiality of this scientific work.

\section{References}

Asfari M, Janjic D, Meda P, Li G, Halban PA \& Wollheim CB 1992 Establishment of 2-mercaptoethanol-dependent differentiated insulin-secreting cell lines. Endocrinology 130 167-178.

Bell GI, Pictet RL, Rutter WJ, Cordell B, Tischer E \& Goodman HM 1980 Sequence of the human insulin gene. Nature 284 26-32.

Boam DS, Clark AR \& Docherty K 1990 Positive and negative regulation of the human insulin gene by multiple trans-acting factors. Journal of Biological Chemistry 265 8285-8296.

Chepurny OG, Hussain MA \& Holz GG 2002 Exendin-4 as a stimulator of rat insulin I gene promoter activity via bZIP/CRE interactions sensitive to serine/threonine protein kinase inhibitor Ro 31-8220. Endocrinology 143 2303-2313.

Clark AR \& Docherty K 1992 The insulin gene. In Insulin: Molecular Biology to Pathology, pp 37-63. Eds FM Ashcroft \& SJ Ashcroft. Oxford: IRL Press.

Dignam JD, Lebovitz RM \& Roeder RG 1983 Accurate transcription initiation by RNA polymerase II in a soluble extract from isolated mammalian nuclei. Nucleic Acids Research 11 1475-1489.

Doyle ME \& Egan JM 2001 Glucagon-like peptide-1. Recent Progress in Hormone Research 56 377-399.

Drucker DJ 2001 Minireview: the glucagon-like peptides. Endocrinology 142 521-527.

Drucker DJ, Philippe J, Mojsov S, Chick WL \& Habener JF 1987 Glucagon-like peptide I stimulates insulin gene expression and increases cyclic AMP levels in a rat islet cell line. PNAS $\mathbf{8 4}$ $3434-3438$.

Edvell A \& Lindstrom P 1999 Initiation of increased pancreatic islet growth in young normoglycemic mice (Umea $+/-$ ). Endocrinology $140778-783$

Fehmann HC \& Habener JF 1992 Insulinotropic hormone glucagon-like peptide-I(7-37) stimulation of proinsulin gene expression and proinsulin biosynthesis in insulinoma beta TC-1 cells. Endocrinology 130 159-166.
German M, Ashcroft S, Docherty K, Edlund H, Edlund T, Goodison S, Imura H, Kennedy G, Madsen O \& Melloul D 1995 The insulin gene promoter. A simplified nomenclature [letter]. Diabetes 44 1002-1004.

Habener JH 2001 Glucagonlike peptide-1 agonist stimulation of Beta cell growth and development. Current Opinion in Endocrinology and Diabetes 8 74-81.

Han XG \& Tuch BE 2001 Cloning and characterization of porcine insulin gene. Comparative Biochemistry and Physiology Part B: Biochemistry and Molecular Biology 129 87-95.

Hedges BS \& Kumar S 2003 Genomic clocks and evolutionary timescales. Trends in Genetics 19 200-206.

Holz GG, Kuhtreiber WM \& Habener JF 1993 Pancreatic beta-cells are rendered glucose-competent by the insulinotropic hormone glucagon-like peptide-1(7-37). Nature 361 362-365.

Inada A, Someya Y, Yamada Y, Ihara Y, Kubota A, Ban N, Watanabe R, Tsuda K \& Seino Y 1999 The cyclic AMP response element modulator family regulates the insulin gene transcription by interacting with transcription factor IID. Journal of Biological Chemistry 274 21095-21103.

Inagaki N, Maekawa T, Sudo T, Ishii S, Seino Y \& Imura H 1992 c-Jun represses the human insulin promoter activity that depends on multiple cAMP response elements. PNAS 89 1045-1049.

Itier JM, Douhet P, Desbois P, Joshi RL, Dandoy-Dron F, Jami J \& Bucchini D 1996 Human insulin gene expression in transgenic mice: mutational analysis of the regulatory region. Differentiation 60 309-316.

Kemp DM \& Habener JF 2001 Insulinotropic hormone glucagon-like peptide 1 (GLP-1) activation of insulin gene promoter inhibited by p38 mitogen-activated protein kinase. Endocrinology 142 1179-1187.

Kieffer TJ \& Habener JF 1999 The glucagon-like peptides. Endocrine Reviews 20 876-913.

Knop FK, Vilsboll T, Larsen S, Madsbad S, Holst JJ \& Krarup T 2003 No hypoglycemia after subcutaneous administration of glucagon-like peptide- 1 in lean type 2 diabetic patients and in patients with diabetes secondary to chronic pancreatitis. Diabetes Care 26 2581-2587.

Komatsu R, Matsuyama T, Namba M, Watanabe N, Itoh H, Kono N \& Tarui S 1989 Glucagonostatic and insulinotropic action of glucagonlike peptide I-(7-36)-amide. Diabetes 38 902-905.

Macfarlane WM, Cragg H, Docherty HM, Read ML, James RF, Aynsley-Green A \& Docherty K 1997 Impaired expression of transcription factor IUF1 in a pancreatic beta-cell line derived from a patient with persistent hyperinsulinaemic hypoglycaemia of infancy (nesidioblastosis). FEBS Letters 413 304-308.

Melloul D, Marshak S \& Cerasi E 2002 Regulation of insulin gene transcription. Diabetologia 45 309-326.

Nauck MA, Niedereichholz U, Ettler R, Holst JJ, Orskov C, Ritzel R \& Schmiegel WH 1997 Glucagon-like peptide 1 inhibition of gastric emptying outweighs its insulinotropic effects in healthy humans. American Journal of Physiology - Endocrinology and Metabolism 273 E981-E988.

Philippe J \& Missotten M 1990 Functional characterization of a cAMP-responsive element of the rat insulin I gene. Journal of Biological Chemistry 265 1465-1469.

Sander M, Griffen SC, Huang J \& German MS 1998 A novel glucose-responsive element in the human insulin gene functions uniquely in primary cultured islets. PNAS 95 11572-11577.

Seino S, Steiner DF \& Bell GI 1987 Sequence of a New World primate insulin having low biological potency and immunoreactivity. PNAS 84 7423-7427.

Seino S, Bell GI \& Li WH 1992 Sequences of primate insulin genes support the hypothesis of a slower rate of molecular evolution in humans and apes than in monkeys. Molecular Biology and Evolution 9 193-203.

Skoglund G, Hussain MA \& Holz GG 2000 Glucagon-like peptide 1 stimulates insulin gene promoter activity by protein kinase A-independent activation of the rat insulin I gene cAMP response element. Diabetes 49 1156-1164. 
Stoffers DA, Kieffer TJ, Hussain MA, Drucker DJ, Bonner-Weir S, Habener JF \& Egan JM 2000 Insulinotropic glucagon-like peptide 1 agonists stimulate expression of homeodomain protein IDX-1 and increase islet size in mouse pancreas. Diabetes 49 741-748.

Thorens B 1992 Expression cloning of the pancreatic beta cell receptor for the gluco-incretin hormone glucagon-like peptide 1. PNAS $\mathbf{8 9}$ $8641-8645$

Tomonari A, Yoshimoto K, Tanaka M, Iwahana H, Miyazaki J \& Itakura M 1996 GGAAAT motifs play a major role in transcriptional activity of the human insulin gene in a pancreatic islet beta-cell line MIN6. Diabetologia 39 1462-1468.

Turton MD, O'Shea D, Gunn I, Beak SA, Edwards CM, Meeran K, Choi SJ, Taylor GM, Heath MM, Lambert PD, Wilding JP, Smith DM, Ghatei MA, Herbert J \& Bloom SR 1996 A role for glucagon-like peptide- 1 in the central regulation of feeding. Nature 379 69-72.

Vincent BJ, Myers JS, Ho HJ, Kilroy GE, Walker JA, Watkins WS, Jorde LB \& Batzer MA 2003 Following the LINEs: an analysis of primate genomic variation at human-specific LINE-1 insertion sites. Molecular Biology and Evolution 20 1338-1348.
Willms B, Werner J, Holst JJ, Orskov C, Creutzfeldt W \& Nauck MA 1996 Gastric emptying, glucose responses, and insulin secretion after a liquid test meal: effects of exogenous glucagon-like peptide-1 (GLP-1)-(7-36) amide in type 2 (noninsulin-dependent) diabetic patients. Journal of Clinical Endocrinology and Metabolism 81 327-332.

Xu G, Stoffers DA, Habener JF \& Bonner-Weir S 1999 Exendin-4 stimulates both beta-cell replication and neogenesis, resulting in increased beta-cell mass and improved glucose tolerance in diabetic rats. Diabetes 48 2270-2276.

Zander M, Madsbad S, Madsen JL \& Holst JJ 2002 Effect of 6-week course of glucagon-like peptide 1 on glycaemic control, insulin sensitivity, and beta-cell function in type 2 diabetes: a parallel-group study. Lancet 359 824-830.

Zhou J, Wang X, Pineyro MA \& Egan JM 1999 Glucagon-like peptide 1 and exendin-4 convert pancreatic AR42J cells into glucagon- and insulin-producing cells. Diabetes 48 2358-2366.

Received 28 February 2005

Accepted 27 May 2005 